\title{
Sublime Experience for Sustainable Underground Space: Integration of the Artists' Works in Chichu Art Museum
}

\author{
Eun Joo Park ${ }^{1, *}$ (i) and Eunki Kang ${ }^{2, *}$ \\ 1 Department of Architecture, Sejong University, Seoul 05006, Korea \\ 2 Department of Architecture, Seoul National University, Seoul 08826, Korea \\ * Correspondence: ej_park@sejong.ac.kr (E.J.P.); ollin00@snu.ac.kr (E.K.)
}

check for

updates

Citation: Park, E.J.; Kang, E. Sublime Experience for Sustainable

Underground Space: Integration of the Artists' Works in Chichu Art

Museum. Sustainability 2021, 13, 6653. https:/ / doi.org/10.3390/su13126653

Academic Editors:

Carmela Cucuzzella,

Cynthia Hammond and

Jean-Pierre Chupin

Received: 10 May 2021

Accepted: 8 June 2021

Published: 10 June 2021

Publisher's Note: MDPI stays neutral with regard to jurisdictional claims in published maps and institutional affiliations.

Copyright: (C) 2021 by the authors. Licensee MDPI, Basel, Switzerland. This article is an open access article distributed under the terms and conditions of the Creative Commons Attribution (CC BY) license (https:/ / creativecommons.org/licenses/by/ $4.0 /)$.

\begin{abstract}
This paper investigates a vision of the underground environment associated with an aesthetic discipline. Its fundamental notion is sublimity, which was a phenomenon that involved a number of artworks engaged with changing the perception of the underground experience. This paper seeks to clarify how the idea of the living environment underground has changed by examining the works of writers, painters, and architects who have drawn inspiration from the concept of imaginary underworlds. Through a case study of the Chichu Art Museum, a representative underground space in terms of a sustainable relationship between architectural spaces and nature that could be experienced as sublime, this paper considers how to integrate visitors to distribute their awareness of artists' work. It also stimulates visitors' perceptions of a more sustainable future through sublime experiences, offering a way to understand underground integration with artworks. Therefore, this paper contributes to the knowledge of the relationship between architecture and artwork by increasing the aesthetic value of the underground space and considering how art intervenes in architecture to create a sustainable didactic.
\end{abstract}

Keywords: sublime experiences; underground spaces; sustainability; artworks; Chichu Art Museum

\section{Introduction}

There is a growing interest in securing new spaces within a limited area as contemporary cities are becoming overcrowded [1-4]. Further, urban development has lost its relationship with the city, along with its urban identity, and has not been concerned about the history of the site [5-8], its so-called context. Philosopher S. K. Langer described the relationship between architecture and place as follows: "Architecture visualizes the characteristics of a place" [9]. The essence of architecture is marked on a place with each unique characteristic, and architecture always takes root in the place and makes its shape with its meaning. Placeness includes not only the visible material things but also the cultural and social meanings, which represent the historical site with a significant collection of memories and history $[10,11]$. Heidegger also said that "the place reveals the bond between the world and the outside and places the human in a way that confirms the depth of the human freedom and reality" [12]. The place is a profound and complex aspect of the human experience in the world $[13,14]$. In this way, the place means more than the location of the architectural form as a unit of the urban environment; it is a fusion of human intention and natural order that can be distinguished from other places, especially in the underground. In addition, the natural and social phenomena of the underground space allow us to approach meaningful architecture by understanding and reading the context of the site.

The development of the underground space through the historical construction of a site has been considered an alternative to improving the urban environment $[3,15]$. The development of underground spaces has the advantage of minimizing the destruction of the natural environment on the ground and can contribute to solving the problems caused by the overcrowding of urban areas. The underground space has been regarded as a safe dwelling, which started as a shelter from the dangers of nature; as a religiously sacred 
space in ancient civilizations; as the world of the dead; as a space containing a mythology of fear. Thus, underground spaces have not been diversified as a result of their restrictive and negative image, nor have they been valued as a major spatial resource for future-oriented urban development. However, the underground has the potential to create a sustainable green space by comfortably preserving and using the natural and cultural resources of the above-ground space [3].

Recently, unconscious connections to architecture have again become the subject of research. The unconscious is one of the few areas where alternative narratives are still possible, and there is nothing more strategic about inserting the unconscious into areas dominated by rational thought such as architecture [16].The architectural metaphors and perceptual, imaginative and spatial of theories are rich sources of understanding that architects create spaces that responds to unconscious desire [16]. Yet, the function of aesthetic experiences based on emotion, feeling, and even imagination in the process of shaping environmental attitudes, has not been considered and verified [17]. Moreover, its significance as it relates to underground spaces has not been adequately assessed. Thus, this study seeks to ascertain the possibility of its application in underground architecture and artworks and searches for a sustainable vision of the underground space. In other words, it presents the underground space as an alternative space to the sublime experience of the aesthetic interpretation of the artists' works, triggered by the development of the underground space.

By solving the problem of aesthetic interpretation recently raised in response to the concept of the sublime in the underground space [3], this study considers the possibility of urban application and tries to locate the aesthetic horizon of the future underground space through the sublime as an aesthetic concept of a new era. To achieve this, this paper:

1. Reinterprets the notion of the sublime experience through the imagination, as shown in artforms such as myths, novels, and paintings (in Section 2.1);

2. Locates the concept and meaning of sublime experience within the aesthetic discussion that can be had in underground spaces (in Section 2.2);

3. Analyzes the Chichu Art Museum in Japan as the representative underground museum, in terms of sustainable relations between architectural spaces and nature, such as through light, darkness and geometric form, with sublime experiences based on the correlations between architectural spaces and artworks (in Section 3).

In this way, this study investigates how the underground spaces are integrated with the artworks, which have altered the visual and sensory experiences. Thus, the purpose of this study is to deal with the nature of space, engaging with the site through aesthetic analysis, rather than functional and technical analyses of the underground space. From the perspective of these analyses, this paper addresses how the vision of the underground could be transformed by the integration of the artworks to create a sustainable environment in the future.

\section{The Sublime, the Underground and Artworks}

\subsection{The Sublime Experience}

Philosopher Jean-Luc Nancy called the sublime "a fashion that has never been stopped from the beginning of the modern era to our time" [18]; the sublime has a different attribute to beauty and has always existed [19]. According to Longinus, the sublime is characterized by the qualities of great oratory: elegant and eloquent phrasing intended to inspire passion [20]. However, the sublime has been neglected for a long time in philosophical aesthetics [21-23]. It was Edmund Burke who animated the modern discussion of the sublime, considering it one of the aesthetic categories. According to Burke, the sublime, unlike the beautiful, is a feeling related to pain or danger that is not threatening to life [24]. The objective bases of beauty and the sublime are actually the opposite. Beautiful tends to refer to small things that may be smooth, diverse, delicate, clear, or bright, while the sublime connotes great qualities, such as uniformity, power, obscurity, and sobriety [25]. Thus, Burke stated: “[ $\mathrm{t}]$ he ideas of the sublime and the beautiful stand on foundations so 
different, that it is hard ... to think of reconciling them in the same subject, without considerably lessening the effect of the one or the other upon the passions" [26]. In the case of the sublime, the imagination utilizes its own capacities of apprehension and comprehension. According to the Kantian point of view, nature has provided us with a sense of both beauty and the sublime by creating the human [27]. Following Burke and Kant, the beautiful and the sublime were categorized to study nature, resulting in artistic outputs, including poetry, painting, and novels. The sublime, a life-changing experience of uncertainty, can be seen as a transformative discourse on the subject [28]. Thus, by the mid-eighteenth century, the sublime had crossed the disciplinary boundaries of literature to incorporate morality and the visual arts as well [27].

Today, the sublime is used colloquially as a vague superlative. The sublime is more than simply an aesthetic trend; it is a holistic experience, encompassing all aspects of life. We find that one of the most consistent claims about this experience is that it involves an element of fear [29]. It has a specific meaning in the realms of philosophy, literary studies, art history, and cultural criticism and may be used to refer to transcendence, insensitivity, exaltation, or ecstasy [30]. More particularly, it is also used to refer to the awe-inspiring, the grandiose, or the great [31].

The sublime provides an alternative and aesthetic path to understanding modernity and allows for an important opening of architectural discourse [26]. In architectural theory, the sublime appears in many ways and it is fundamental to the construction of modern aesthetics, which has restricted our ability to see architecture from a lasting perspective in terms of the sublime. The sublime connotes immense ideas, such as space, time, death, and divinity [27]. Its importance for the subjects of aesthetics and architecture lies in its conceptual scope or spiritual dimension. Thus, this study suggests that the sublime provides alternative and aesthetic ways to understand architectural space, especially underground space. More specifically, it proposes that a series of underground imaginings have changed our environmental visions of architecture to portray a more sustainable future through sublime experiences.

\subsection{A Vision of the Underground Imagination in Art}

Rosalind William observed in "Notes of the Underground" that Sigmund Freud (1856-1935) considered the subterranean metaphor as central to his ideas about the human "subconscious" [32]. Juhani Pallasmaa deals with a psychic understanding of architecture by "opening up a view into a second reality of perception, dreams, forgotten memories and imagination." [33]. Pallasmaa's conception of the unconsciousness is similar to Freud's idea of eccentricity wherein silence sympathizes with the sublime. The phenomenon of underground development began with imaginative literature, and changing perceptions of the living environment. The narrative tradition retained its popularity through the eighteenth century, and numerous scholars and intellectuals have drawn inspiration from the concept of an imaginary nature [34-36], which will continue to fascinate human beings in the future.

The underground space in myth is related to death, which can be attributed to the custom of burying the dead. In Greek and Roman mythology, the underworld is depicted as a conceptual space, revealing a fear that is close to horror and awe, rather than a substantive space, and Hades was the god who governed the underground space (see Figure 1). Fear is considered a component of the sublime. For example, the self-preservative passion of simple fear has pain as a constituent, while the self-preservative passion arises when pain is threatened at a relatively safe distance, or when pain is experienced as a component of moderation, awe, and "tranquility shadowed with horror" [26]. In other words, the underground space is not only a space of fear that alienates human beings [37]; it is also a space of death from which humans want to turn away, despite being part of nature. 


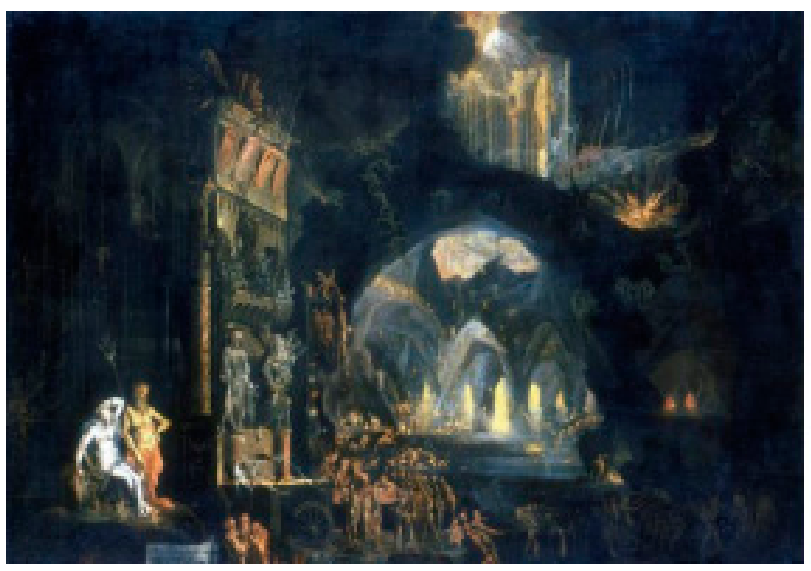

Figure 1. Hell, François de Nomé, 1622 (Source: Wikimedia Commons) [38].

Similarly, French novelist Jules Verne's (1828-1905) science fiction is best known for a variety of innovations and technological advancements. In Verne's book "A Journey to the Center of the Earth" [39], etching images illustrate the voyage into the "darkness" of the underground, and the book described the underworld in such a way as to explain intense emotion as a source of fear but also as the pleasure of the undiscovered world, which is emphasized as a metaphor for the Romantic movement [40].The narrative alternates scientific research with claustrophobia and acute representations of the challenges and feelings of fear and pleasure as they are experienced by an individual endowed with incredible perceptibility and creative imagination. The heroes in the novels rely on intermittent light, which gradually brightens to present spaces that were concealed in darkness (see Figure 2). Moreover, the dark spaces are where the psychological space expands to become the experience of the sublime. Through intense light, the dark space is perceived by the audience and this darkness expands into the space of the sublime experience.
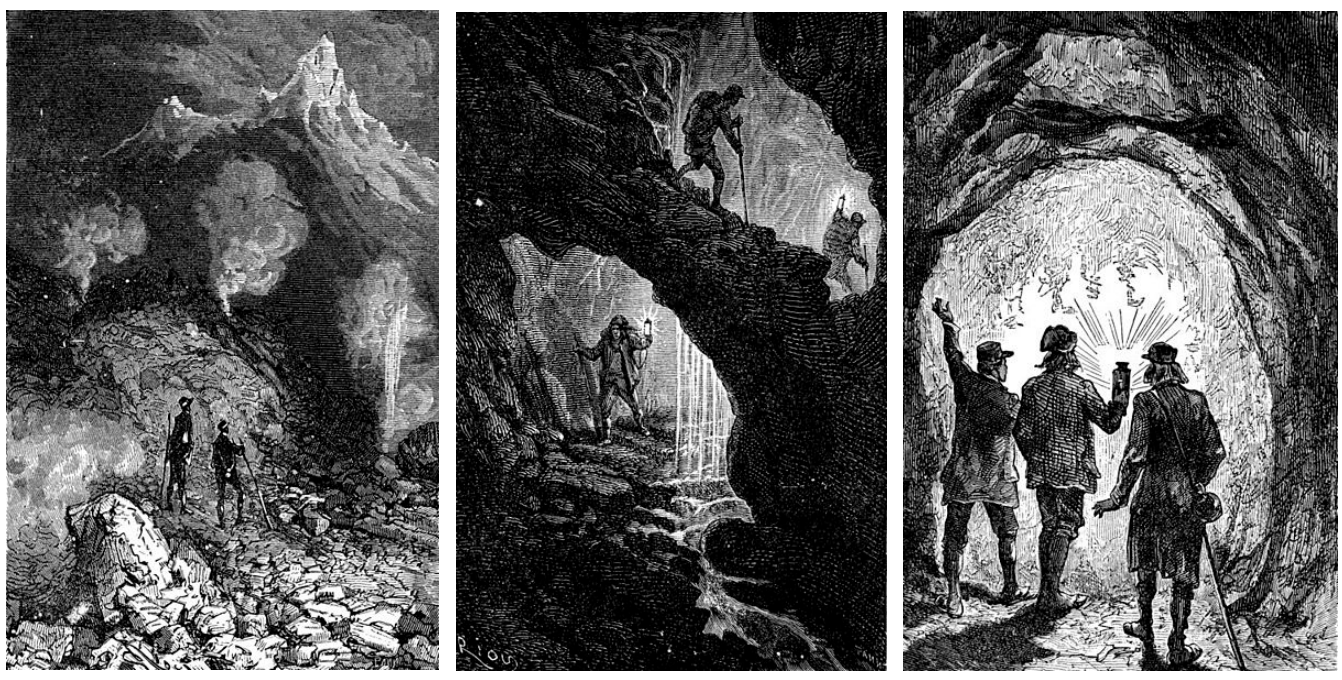

Figure 2. An illustration from the novel "A Journey to the Center of the Earth" by Jules Verne, painted and illustrated by Édouard Riou. These etchings depict the creatures encountered in the imagination of the subterranean landscapes through which they pass (Source: Wikimedia Commons) [41].

“Le Carceri d'Invenzione (Imaginary Prisons)" by Giovanni Battista Piranesi (1761) epitomizes the archetype of fabricated vastness and, as such, represents the underground in architectural constructions. Piranesi created a prodigious oeuvre of dynamic and curious images of magnificent buildings and mysterious prisons. While not literally underground, they convey an overwhelming sense of enclosed spaces and an infinite subterranean environment [42]. Piranesi's poetic imagination of infinite space, with its contrasts between 
light and dark, large and small, appears as a model of romanticism. As Burke suggests, feelings of sublimity might be aroused by external nature and the "artificial infinite," a nonorganic visual object of great dimensions [26]. Inside these prisons, it is possible to imagine an empty silence through infinite space and the colossal architectural structuresinfinite staircases and arching domes, narrow corridors and impenetrable fortifications, columns, chains, and furnaces (see Figure 3).

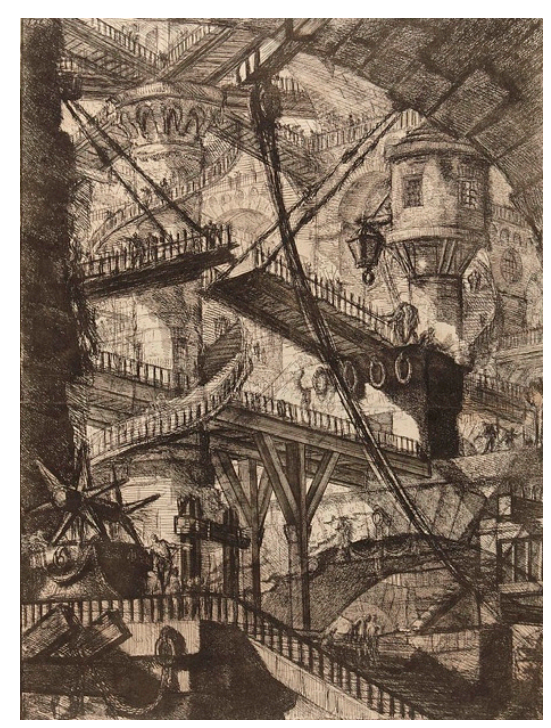

Figure 3. Giovanni Battista Piranesi, “The Imaginary Prisons (Le Carceri d'Invenzione”, plate VII: The Drawbridge) (Source: Princeton University Art Museum) [43].

Architecture, sculpture, and painting once belonged together. Indeed, they were admirably intertwined at various points in history. During relatively recent times in human civilization, the separation of art and architecture has taken place, resulting in the application of a new aesthetic principle of the sublime to the unknown underground space. The underground can be viewed as the symbol of the development of the perception of the city, and it illustrates the desire for the aesthetic through imaginative and technological achievements. It is worth revisiting past visions of underground imaginings that could influence the urban environment of the future. Numerous scholars and intellectuals have drawn inspiration from the concept of an imaginary underworld, which will continue to fascinate human beings in the future as well.

\subsection{Framework}

From the representation of the underground space presented above, a new fascinating vision emerged, which introduced models of the human environment for the future [44]. The underworld is something entirely different, neither nasty nor beautiful. In addition, underground spaces were not only characterized by fear, but were also seen as evocative of the pleasant darkness and infinite space of the unknown world, offering new possibilities for expressing a vision of undiscovered underground spaces. The analysis framework was derived from the underground spaces shown in Section 2.2 and extended to factors related to the characteristics of sublime experiences (see Table 1). 
Table 1. Characteristics of the sublime experience in imaginings of the underground (Source: Authors).

\begin{tabular}{|c|c|c|c|}
\hline & Myth & Noble & Painting \\
\hline Imagination Medium & François de Nomé, “Hell” (1622) & $\begin{array}{l}\text { Jules Verne, "Journey to the } \\
\text { Center of the Earth" (1864) }\end{array}$ & $\begin{array}{l}\text { Giovanni Battista Piranesi, } \\
\text { "Imaginary Prison" (1761) }\end{array}$ \\
\hline Characteristics & $\begin{array}{l}\text { - fear close to horror and awe } \\
\text { - } \quad \text { fear has pain as a constituent } \\
\text { - dated to death } \\
\text { - } \quad \text { natural mysterious space } \\
\text { - }\end{array}$ & 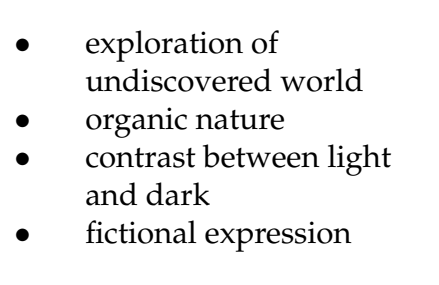 & $\begin{array}{ll}\text { - } & \text { materialized in } \\
\text { - } & \text { architectural constructions } \\
\text { - } & \text { infinity stairs } \\
\text { - } & \text { endless spaces } \\
\text { - } & \text { nonorganic visual object } \\
& \text { of great dimensions }\end{array}$ \\
\hline $\begin{array}{c}\text { Summary of } \\
\text { Sublime Experience }\end{array}$ & \multicolumn{3}{|c|}{$\begin{array}{l}\text { - underground spaces are characterized not only by fear, but also by the pleasant darkness and } \\
\text { infinite space of the unknown world } \\
\text { - } \quad \text { the dark space gradually becomes bright, expanding into the space of the sublime experience } \\
\text { - infinite spaces are depicted with contrast between light and darkness to arouse the imagination }\end{array}$} \\
\hline
\end{tabular}

\section{The Sublime Experience Underground: A Review}

\subsection{Context: Chichu Art Museum in Naoshima}

Naoshima is a small island with 3400 inhabitants and an area of $14.22 \mathrm{~km}^{2}$ that belongs to the Kagawa Prefecture, the northernmost of the four prefectures of the island of Shikoku in the administrative territory of Japan. Naoshima was economically booming when Mitsubishi Mining established a copper smelter in 1917, but it became heavily polluted by heavy metal waste as it was used as an industrial waste treatment plant until the 1980s [45]. The fortune of the island, which has lost its vitality, has changed as a result of the efforts of local governments and citizens to revive the abandoned island. In 1989, Benesse Holdings, a Japanese publishing and education company, invested in a culture and arts center for the island with the intention to "make the islands destroyed by people beautiful with human hands" [46]. To overcome these problems, sustainable development efforts have begun that combine the areas of environmental preservation and art. Naoshima is now described as having been transformed from a garbage island to an art island [47]. Tadao Ando, the architect who designed the Benese Group center and carried out major projects for sustainable development, was integral to this transformation [48].

The Chichu Art Museum played a major role in transforming Naoshima into an art island. In 2004, Tadao Ando completed the museum, which was built under a hill, on the southern slope on which a salt mound remained. Chichu means underground, and the museum humbly hides in the ground so that its appearance is not visible from the entrance (Figure 4).

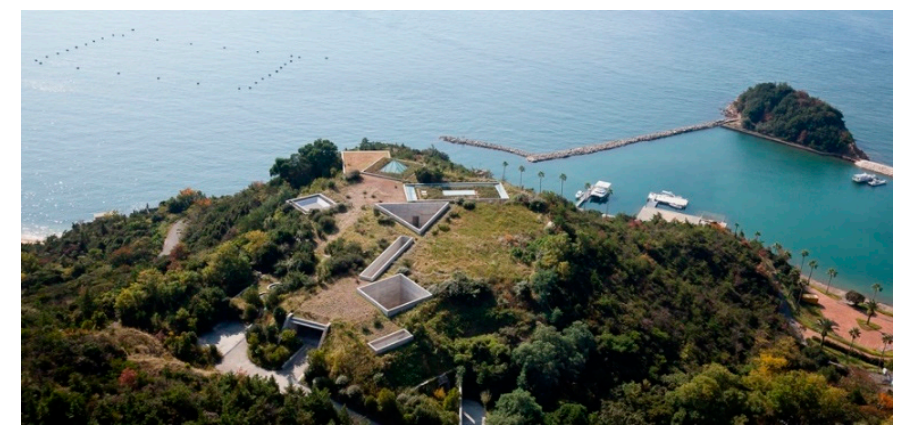

Figure 4. A view of the Chichu Art Museum from the sky. To avoid undermining the natural landscape, the building was constructed underground. (Source: Benesse Art Site Naoshima) [49]. 
Ando said: "Darkness rather than the light, below ground rather than above-the Chichu Art Museum is the most direct expression of this feeling rooted deep inside me" [50].

To adapt to the natural environment, Ando realized his architectural concept of not enacting violence on the ridgelines, skylines, and horizons of the surrounding islands in such an extreme way that so-called context and architecture of nature co-exist at the site. Even though the museum is in underground, naturally designed skylights and window ceilings were used to bring natural light into the underground space, and to enable people to feel the changes in nature, such as light, wind, and rain.

\subsection{The Sublime Experience of the Chichu Art Museum \\ 3.2.1. The Architectural Languages}

The Chichu Art Museum comprises three floors, and its structure is divided into an entrance area, two courtyards and three art spaces located underground. The composition of the Chichu Art Museum is based on the forms of a square, hexagon, and triangle, with two voids on the north and south axes allowing a view from the top of the hill to the sea. The architect sought to achieve a highly complex and varied sequence of sublime experiences for visitors within a configuration of simple, geometrical forms. Ando carved volumes into the earth and tried install in them a sense of further depth, which inevitably resulted in less light and an intensified atmosphere [50]. He examined every aspect of the amount and quality of light penetrating the darkness and highlighting the individual spaces, making each distinctive. The museum was intended to guide the visitor by the use of light. Through Ando's architectural language, the museum reproduces the sublime experience-related to spaces of fear and darkness, and to infinite spaces-in the form of a sustainable building (see Figure 5).

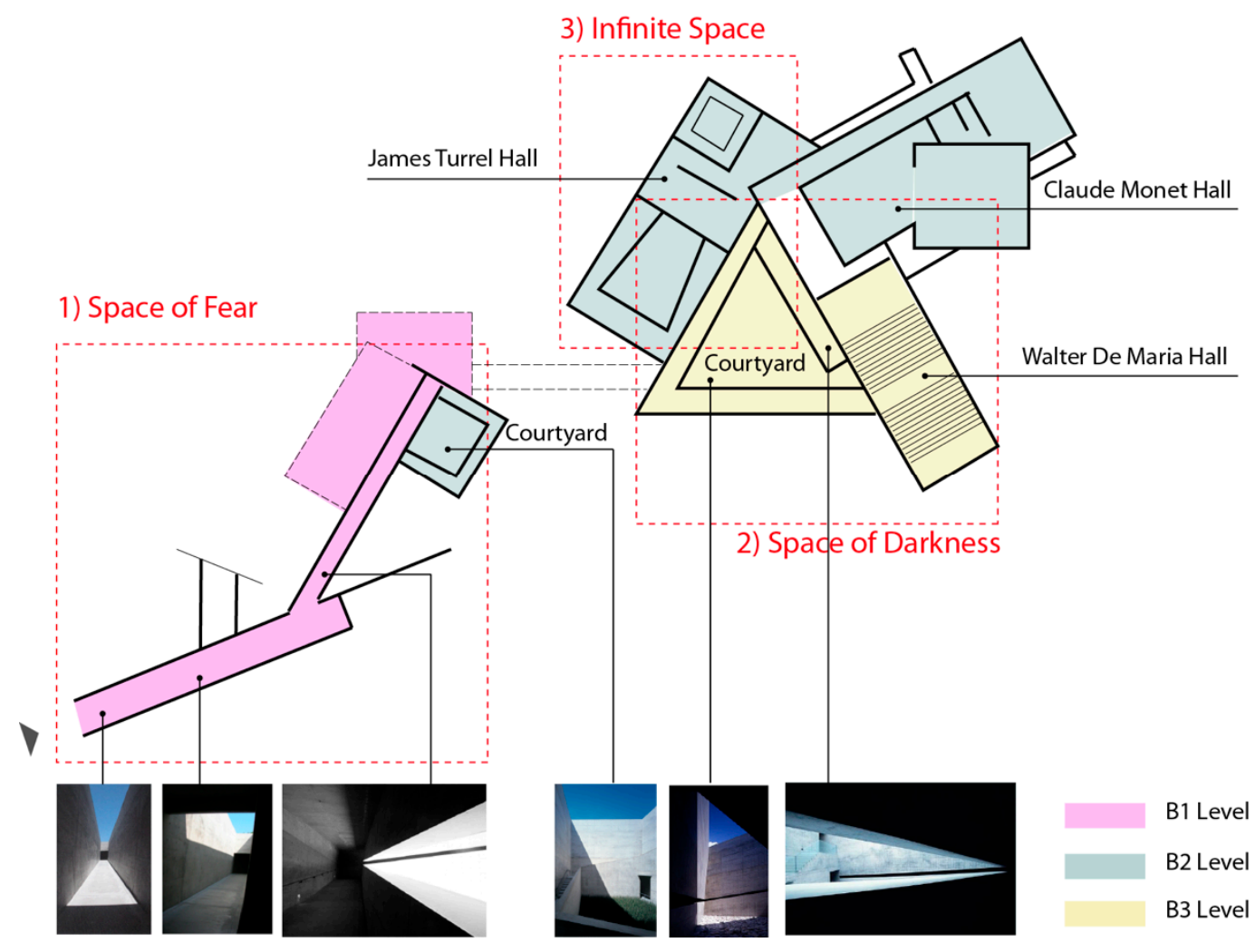

Figure 5. Plan diagram of the Chichu Art Museum (Source: author's drawing). 


\subsubsection{The Entrance and Corridor}

The entrance of the museum meets at a sharp angle from the long concrete wall following the stairs of the two-story square garden underground. The walls have the characteristic of intentionally turning the lines that connecting the spaces so that it is impossible to predict the view ahead. This allows visitors to experience the uncertainty of the invisible space. This is a strategy for creating a sublime experience, producing a phenomenological effect that amplifies the anticipation of the museum by the complex flows of visitors, building on the fear of not knowing what is ahead. Visitors walk down the dark angled stairwells made of Ando's signature concrete slabs to an exterior-less gallery and then into a corridor. Ando allows visitors to establish and coordinate relationships with architecture through unique experiences when visiting his architecture. One of the representative characteristics of this unique process is the maze of movement in the underground space. The entrance that passes through the two voids, where the wall meets at an acute angle, does not show the space ahead but filters it, introducing the remaining art spaces as mysterious, while creating a dramatic atmosphere. Moreover, if visitors observe the characteristics of the spatial composition arranged according to the flow of movement, the bright and dark spaces alternately repeat as they move, leading to a new experience that always changes according to the contrasts and developments in the light (see Figure 5).

\subsubsection{Two Courtyards}

Stairs and lamps are vertically connected between the art spaces of the museum, which can be experienced in different directions, as the visitor chooses the route. To access the square courtyard, visitors must pass through a long and narrow corridor in darkness. The labyrinthine movement from the entrance to the art spaces gives visitors a sense of fear in the unknown space even before they view the artwork. A square and a triangle-shaped courtyard are located in the center, and sunken spaces run around each area. These two areas are connected by an outdoor passage, akin to a trench. At the end of the corridor, a bright light from a window creates a beautiful contrast and arouses curiosity about the space on the bright side. As visitors progress, little by little, along the dramatic beam of light from the entrance, a series of geometric shapes are formed between the concrete walls, and light, blue sky, green space, and fresh air alternate in the frame. The slight light in the darkness makes the space appear to converge at the surface of the museum in the ground, creating a refracted space and evoking a gradual change of emotion from fear to pleasure. The outdoor aisle is open towards the sky, which visitors can see from the underground space, experiencing the natural light, wind, rain, and clouds directly. This is reflected in Ando's architectural conception of "the coexistence of people, architecture, and nature" [46]. Thus, the museum in the darkness is a mysterious space that enhances curiosity and expectations about "what is ahead?" because it is difficult to predict the space that will meet in the middle of nowhere.

\subsection{Architecture Integration of Artists' Works}

The Chichu Art Museum exhibits only three artists' works, including a monumental sculpture by Walter de Maria, meditative light installations by James Turrell, and a series of Claude Monet's incomparable "Water Lilies". Ando has created a specific art space for each work. This section explores how the spaces integrate the central concepts of these three artists' works.

\subsubsection{James Turrell}

When visitors arrive at the art space for the "Open Field" by James Turrell, they can see a screen full of walls (see Figure 6a). The "Open Field" was designed to make the ceiling gradually higher by planning an inclined floor section toward the inside of the room, with an entrance of $3200 \mathrm{~mm}$ and the inside of the room at $3900 \mathrm{~mm}$. This effect is also achieved through a slanted floor section approaching the room. As visitors climb the stairs and move carefully toward the screen, the screen wall that they expect to hit 
turns into a blue space, which they can enter into with a fear of not knowing what is ahead. James Turrell treats light itself as matter, which is the essence of his work. When visitors move up and down the stairs, the scenery and shadows reflected on the light and sphere change depending on the position and angle of the viewer, and the feelings of the viewer also change.
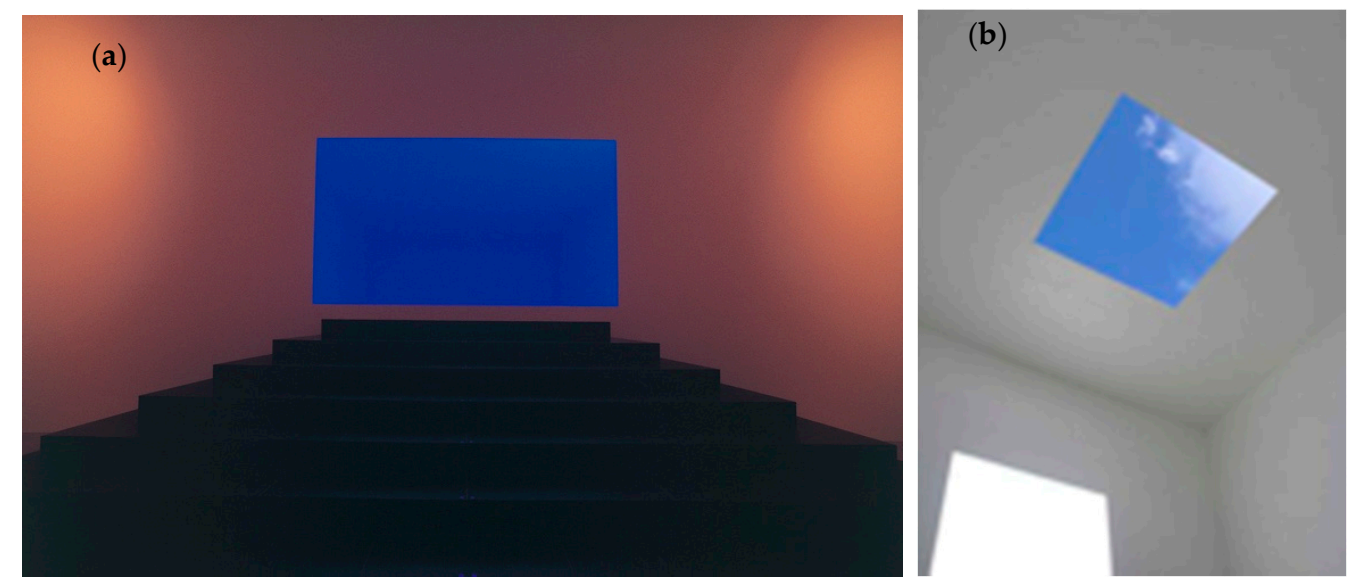

Figure 6. (a) “Open Field”, (b) “Open Sky” (Source: Benesse Art Site Naoshima) [49].

“Open Sky" provokes a mysterious experience, as if an infinite space is connected to it (see Figure 6b). The "Open Sky" art spaces have an $8000 \mathrm{~mm}$ ceiling housing a square opening that fully exposes the center of the pavilion to the sky. Before entering the "Open Sky," the $4500 \mathrm{~mm}$-high space was $3500 \mathrm{~mm}$ lower than the main art space under the "Open Sky." By this height difference, Ando tried to provide a dynamic impression with a contrast between the two spaces. This is a strategy to emphasize the verticality of the exhibition by designing the entire room at the beginning. The entrance and the surroundings are low and dark, so the viewer enters the art space with low expectations, meaning that the bright and high art space produces an even greater impression, which is dependent on the sense of inversion. The dizzying ceiling height, texturally rich materials, and mathematically precise installation create a deeply reverential and meditative space capable of inspiring a sense of awe.

\subsubsection{Claude Monet}

The museum mostly depends on natural light; thus, its corridors are cool and dark, while the galleries are large and bright. This simple differentiation heightens the experience of entering the art space by allowing viewers to have a visual stimulus. At the entrance to Monet's art space, visitors are able to see the vivid greens and blues bursting from canvases that seem less like flat surfaces than portals to fecund preternatural scenes within a brilliant white interior with rounded walls that create an edgeless impression of infinity. The size, design, and materials of the room were all carefully selected by the architect to combine Monet's paintings with the surrounding space. Monet's art space uses natural light, which seeps in through the crevices where the walls and ceiling meet, to remove the setting. This allows visitors to view the paintings in light, which changes the overall tone of the works, depending on the season, weather, or time of day.

\subsubsection{Walter de Maria}

After passing through a narrow and dark corridor, visitors are able to meet de Maria's installation "Time/Timeless/No Time", a giant orb in the middle of stairs set in the center of a 10-m-wide concrete art space (see Figure 7). The large-scale artwork in the concrete room, surrounded by Ando's architectural language, reminds visitors how the space of the artwork can expand their perceptions of and pleasure in artistic experiences. The artwork transforms the natural light and surrounds the glowing walls with gold rectangles. 
The clarity and deliberation of the architect's creation are noticeably activated. The space features a cross-sectional plan that gives depth and visual effect by creating changes in the ceiling, while the staircase progresses from the entrance across the entire room in the direction of the gaze. To introduce natural light, glass skylights were planned on four sides along the center and outer corners of the art space. The light falls through a deep gap on the side of the room and is filtered through a much softer and more subtle light on the wall. As de Maria stated, "In my life and work I seek ... the right place, the right action, the right time" [51]. Space and artwork are integrated to emphasize the powerful and delicate sublime experience that gives visitors order and clarity.

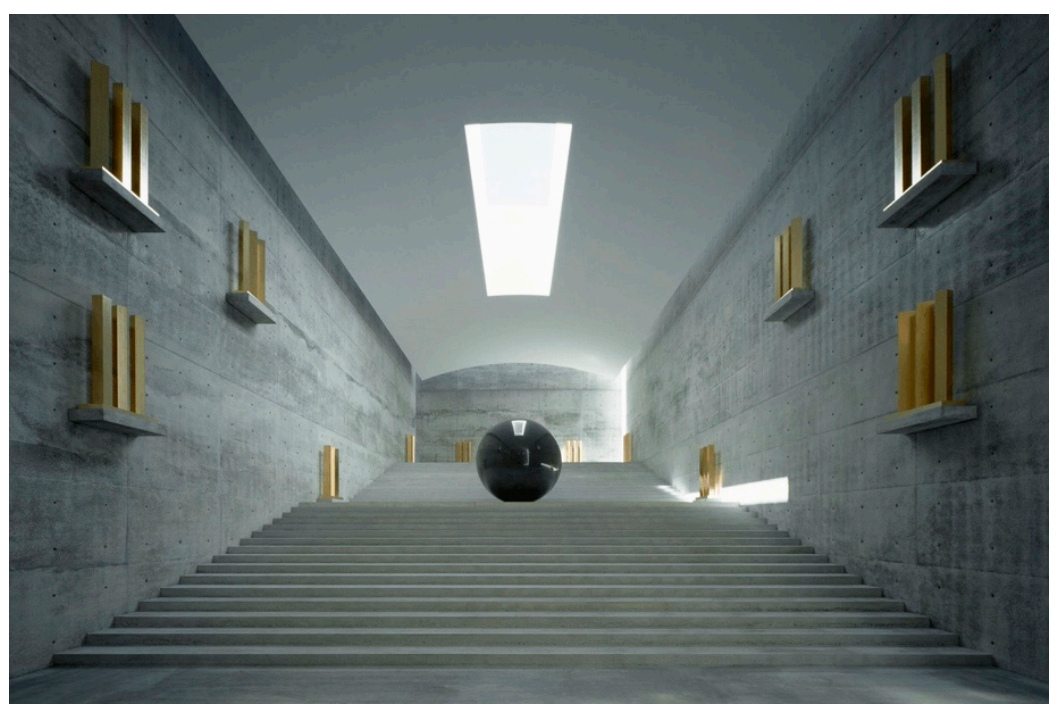

Figure 7. Walter de Maria, “Time/Timeless/No Time” (2004). Chichu Art Museum, Japan. Image (C) Mitsuo Matsuoka (Source: Benesse Art Site Naoshima) [49].

\section{Discussion}

\subsection{The Matrix of the Integration of the Sublime Experience with the Artworks in Chichu Art Museum}

The sublime experience of Chichu Art Museum's integration of its artworks can be divided into three contexts. First, the placeness of natural elements, such as light, wind, and sound from sea and sky, is perceived through the architecture in relation to its surroundings. As Ando regards the beginning of architecture as harmony with the site, he has not destroyed nature, but tried to induce more active cognitive development in response to nature's contrasting effects, enhancing the relationship between nature and the human through architecture [52]. This is why Ando focused on the entire context of the site, adding geometrical artificiality: "[T] he goal is to create a higher level of space of possibility, where art, nature, and humans work together to stimulate each other. I hope that architecture will be a device that can enhance people's imagination and evoke conversations with art or nature" [53]. Following his idea, the appearance of the museum becomes one with nature, buried in nature, and it is not easy to recognize the form of the museum from the outside. The museum occupies only space in the ground and needs no expression on the outside.

Second, the underground museum was conceived as a space in which architecture and artworks would exist as a single entity, where the merging of architecture and art would become apparent. When viewing the artworks of James Turrell, Claude Monet, and Walter de Maria in the Chichu Art Museum, a sublime experience occurs in the spaces where the architect combines geometrical forms and natural elements. Visitors can understand the space by illuminating the dark interior through the flow of light as an underground space made of darkness. The museum provides an experience that encompasses something beyond architecture and the natural environment, incorporating each particular artwork 
and allowing us to perceive and interact with it in different and important ways. When experiencing the art spaces, it becomes clear that the darkness of the spaces at the museum exists in a state of interdependence. That is to say, the sublime experience is as much a contributing element to the display and reception of artists' works in art spaces, and each space is interrelated with the others.

Last, the underground museum provides a sustainable approach to art, encompassing the environment, society, and culture. According to Ando, architecture is a part of the overall environment; hence, he tries to preserve nature around his architecture and to encourage sensitivity to the changes in nature [54]. The persistent characteristics of a place are clearly related to our continuing experience of the change and continuity of that place, or to the nature of the change itself, and this strengthens the relationship between architecture and place. As sustainability is related to the sense of placeness, even when the surrounding is changed, it is felt that this place will last and remain a distinct entity; this is an example of the situation in which architecture and artworks are integrated with the experience of the sublime. The museum provides a place supporting a wide range of sustainable approaches, encompassing the environment, society, and culture.

To explain the sublime experience of integrating architecture and artworks, an analysis of the spatial experience of the artworks in the underground museum based on the architect's language is presented in the matrix shown in Figure 8.

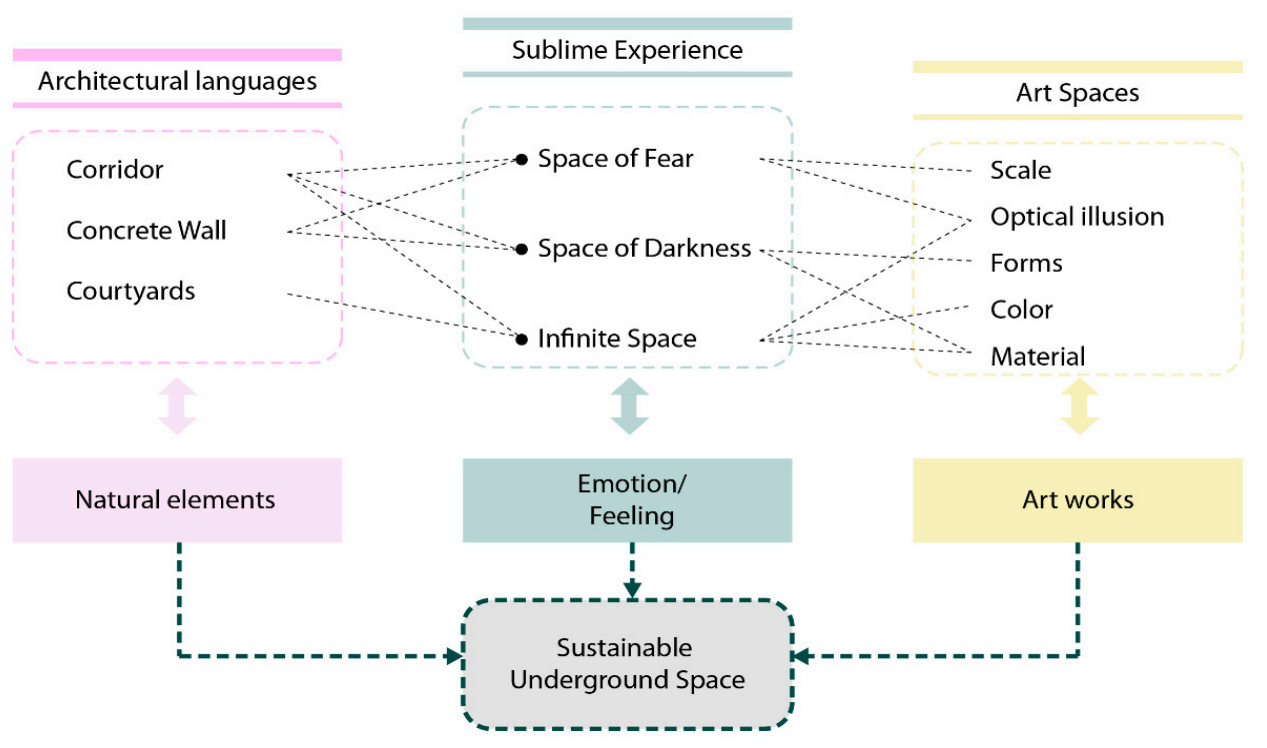

Figure 8. Matrix of sublime experience of artworks in Chichu Art Museum (Source: author's drawing).

\subsection{Synergistic Influence of the Place in Which Art Is Presented on Its Perception}

The general spirit of the place is important in terms of the perception of artistic events. The sublime experience of the space can be transferred to the assessment and impact of the events taking place within it. In this respect, the Chichu Art Museum focuses on sublime experiences that result from changing spaces, provoking different feelings and emotions. The underground museum is minimal in its appearance and material; however, the experience of a continuous space that flows from its entrance throughout its entirety is a reversal of the minimal, continuously introducing new and unexpected spaces that evoke feelings of fear and awe, and also the pleasure of joy.

The underground museum pursues a sustainable vision of an underground environment that embraces nature and adapts to the context of the site, connecting with the surroundings. In addition, the reason why the Chichu Art Museum is more highly appreciated than any other underground space is because of its sustainable relationship between the architectural space and the existing artwork. Ando believes in presenting the beauty 
created by human beings in the colorless space created by nature and breathing life into the architectural space rather than revealing the form or materials of the building.

Sublime experiences and sensibility change from time to time, but this architecture offers a way to introduce poetic and dramatic stories underground. Scenes and spaces are connected by motion and time to form a sequence, and the dramatic transition of these sequences and the flow of the change capture a story as a whole. Architecture is not an object of appreciation, such as a work of art that is only to be observed, but an object of experience and perception by all senses. Therefore, the Chichu Art Museum pursues a sustainable vision of the underground environment, which is completed by the experiences of those who inhabit and experience it-that is, the perceptive subject shapes the environment, rather than the architecture itself (Figure 9).

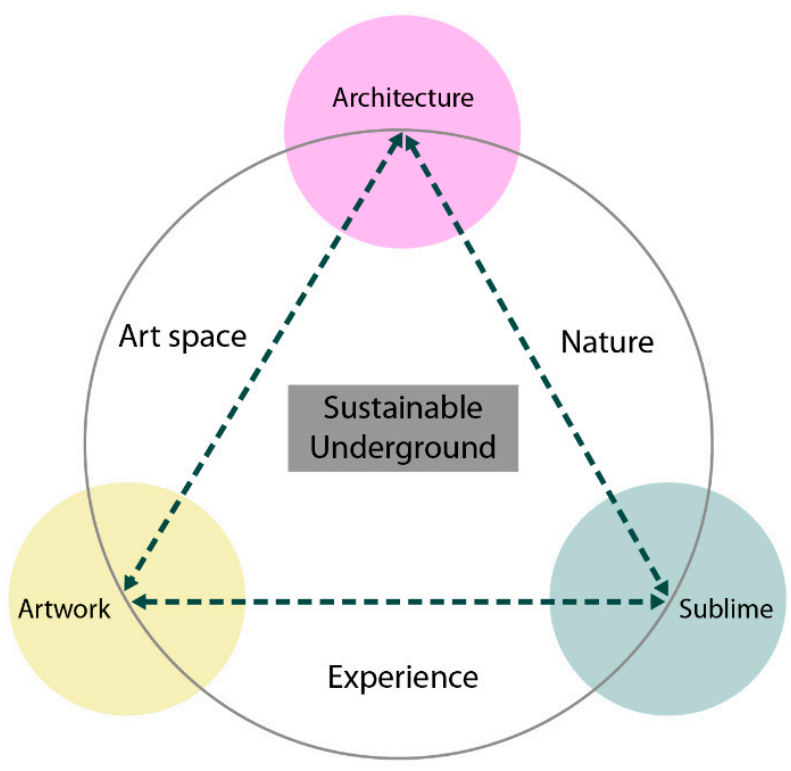

Figure 9. Sustainable model of underground space (Source: author's drawing).

\section{Conclusions}

Underground development represents humankind's pursuit of scientific accomplishments for authenticity, competency, aestheticism, and refuge. However, the increasing intricacies of the underground may result in a change to the prioritization of the requirements of the built environment and those of the people. Reliance on technology could have a negative effect on social relations and interactions between people, which can also provide a sense of protection, sometimes even more beneficial and efficient than that offered by technology. This study, by solving the problem of aesthetic interpretation recently experienced in the underground space-the concept of the sublime experience-clarified the working processes of the senses, discussed the development of the underground to evoke the sublime, and presented this alternative as an aesthetic concept for a new era.

Historically, the sublime underworld cannot be accurately defined: it is, at the same time, repulsive and appealing; ambiguous and cryptic, but not oppressively so; abhorrent and alluring. Nevertheless, the positive aspects have gained ground; the underworld has been transformed into an enchanted land, a safe haven, free of flaws and deficiencies. Numerous scholars and intellectuals have drawn inspiration from the concept of an imaginary underworld, which continues to fascinate human beings. When considering the possibility of urban application, the aesthetic vision of the underground is found in sublime experience, not in technological accomplishment. Therefore, it is necessary to create a plan for inducing the sublime experience by constructing a history of the underground space, which could diversify its use and support user's cultural and social experiences.

The Chichu Art Museum demonstrates a sustainable vision of an underground environment that embraces nature and adapts to the context of the site, thereby leading 
to the transformation of spaces through different feelings and emotions. The museum provides a harmonious yet enriched space and environment by establishing an organic relationship between the natural environment, humans, and architecture that is called sustainable. The museum is minimal in its appearance and materiality; however, the experience of a continuous space that follows the flow of movements from the entrance, to the entire space, to the exit is a reversal of the minimal, continuously meeting new and unexpected spaces that endow feelings of fear, awe, but pleasure. Thus, the Chichu Art Museum reveals the sustainability of the underground space by eliciting in those who visit this underground space. Sublime experiences and sensibility that change from time to time, as if architecture provides a way to introduce poetic and dramatic stories into the underground. Scenes of space through motion and time are connected to form a sequence, and the dramatic transition of these sequences and the flow of change capture a story as a whole. Architecture is not an object for appreciation, such as a work of art that is only to be looked at, but an object for appreciation experienced and perceived through all our senses and perceptions. Therefore, the Chichu Art Museum pursues a sustainable vision of the underground environment that is completed by adding the experiences of those who visit and experience it, that is, the sensitive subject, rather than the architecture itself.

In short, the underground is a place where you can experience fear, darkness, and infinite spaces integrated with artworks. It reflects not only the imagination of visitors but also the experience of the body, and as a sublime space that gives visitors a sense of place, it is a space of reflection. The spaces and forms of architecture itself are not perfect, but visitors can experience sublime moments through the continuity of architectural elements underground, transformed into a sustainable vision of the urban environment.

The relationship between the architectural space and its artworks creates a sublime experience, leading to new ways of perceiving the underground environment, which enhances our imagination and helps us to find sustainable solutions for an underground future. Further, the sublime experience is significant in the relationship between the architecture and the artworks in the underground space. Therefore, this paper contributes the knowledge concerning the relationship between architecture and artworks as a catalyst for sustainable underground development of strong value of local identity that engages in the conservation of the natural environment. The most important idea is to reverse the current approach that considers only the spatial value of underground buildings to find new underground features and conserve surface space for the future. More discussions will be necessary in order to develop ideas on how artworks affect visitors' experiences behavior in the underground museum, or what sort of sublime experiences can induce to become more powerful, which could be examined in future researches.

Author Contributions: Conceptualization, E.J.P.; methodology, E.J.P. and E.K.; investigation, E.J.P. and E.K.; writing—original draft preparation, E.J.P.; writing—review and editing, E.J.P. and E.K.; visualization, E.J.P.; supervision, E.K. All authors have read and agreed to the published version of the manuscript.

Funding: This research was supported by Sejong University in 2021.

Institutional Review Board Statement: Not applicable.

Informed Consent Statement: Not applicable.

Data Availability Statement: No data is available for this work.

Conflicts of Interest: The authors declare no conflict of interest.

\section{References}

1. Münz, R. Overcrowded World?: Global Population and International Migration; Haus Publishing: London, UK, 2010.

2. Angel, S.; Parent, J.; Civco, D.L.; Blei, A.; Potere, D. The dimensions of global urban expansion: Estimates and projections for all countries 2000-2050. Prog. Plan. 2011, 75, 53-107. [CrossRef]

3. Broere, W. Urban underground space: Solving the problems of today's cities. Tunn. Undergr. Space Technol. 2016, 55, 245-248. [CrossRef] 
4. Durmisevic, S. The future of the underground space. Cities 2016, 16, 233-245. [CrossRef]

5. Sterling, R.; Admiraal, H.; Bobylev, N.; Parker, H.; Godard, J.-P.; Vahaaho, I.; Rogers, C.D.F.; Shi, X.; Hanamura, T. Sustainability Issues for Underground Space in Urban Areas. Urban Des. Plan. 2012, 165, 241-254. [CrossRef]

6. Littlefield, D. (Re)generation: Place, Memory, Identity. Archit. Des. 2012, 82, 8-13. [CrossRef]

7. Abd Elrahman, A.S.; Asaad, M. Urban Design \& Urban Planning: A Critical Analysis to the Theoretical Relationship Gap. Ain Shams Eng. J. 2020, 12, 1163-1173.

8. Aldız, E.; Aydın, D.; Sıramkaya, S.B. Loss of city identities in the process of change: The city of Konya-Turkey. Procedia Soc. Behav. Sci. 2014, 140, 221-233.

9. Susanne, K. Langer, Feeling and Form a Theory of Art (Chapter 6). In The Modes of Virtual Space; Developed from Philosophy in a New Key; Routledge: London, UK, 1953; pp. 86-103.

10. Kern, S. The Culture of Time and Space; Harvard University Press: Cambridge, MA, USA, 1983.

11. Kwinter, S. Architectures of Time: Toward a Theory of the Event in Modernist Culture; The MIT Press: Cambridge, MA, USA, 2002.

12. Heidegger, M. The Question Concerning Technology and Other Essays; Garland Publishing Inc.: New York, NY, USA, $1977 ;$ pp. 3-35.

13. Bachelard, G. The Poetics of Space; Beacon Press: Boston, MA, USA, 1994.

14. Heidegger, M. Building, Dwelling, Thinking. In Poetry, Language, Thought; Duke University Press: New York, NY, USA, 1971; pp. 145-229.

15. Bobylev, N. Mainstreaming sustainable development into a city's Master plan: A case of Urban Underground Space use. Land Use Policy 2009, 26, 1128-1137. [CrossRef]

16. Hendrix, J.S.; Holm, L.E. Architecture and the Unconscious; Routledge: London, UK, 2016.

17. Wang, P.-C.; Yu, C.-Y. Aesthetic Experience as an Essential Factor to Trigger Positive Environmental Consciousness. Sustainability 2018, 10, 1098. [CrossRef]

18. Nancy, J.-L. Du Sublime; 1988 Editions Berlin; Moonji Publishing: Seoul, Korea, 2005; p. 7.

19. Cronk, N. The Classical Sublime: French Neoclassicism and the Language Of Literature; Rookwood Press: Charlottesville, VA, USA, 2003.

20. Roberts, W. Longinus on the Sublime: The Greek Text Edited after the Paris Manuscript; Cambridge University Press: Cambridge, MA, USA, 2011.

21. Lyotard, J.F. Presenting the Unpresentable: The Sublime. Art Forum 1984. Available online: https://www.artforum.com/print/ 198204/ presenting-the-unpresentable-the-sublime-35606 (accessed on 21 March 2021).

22. Theriault, N. The Role of the Sublime in Art, Literature, and Psychology. Ph.D. Thesis, University of Houston, Houston, TX, USA, 2008.

23. Carlson, A. Nature and Landscape: An. Introduction to Environmental Aesthetics; Columbia University Press: New York, NY, USA, 2009.

24. Burke, E. A Philosophical Enquiry into the Sublime and Beautiful and Other Pre-Revolutionary Writings; Wormersley, D., Ed.; Penguin Books: London, UK, 1998.

25. Shelley, J. 18th Century British Aesthetics. 2006. Available online: https://plato.stanford.edu/entries/aesthetics-18th-british/ (accessed on 21 March 2021).

26. Burke, E. On the Sublime and Beautiful; Good Press: Glasgow, UK, 2020.

27. Nesbitt, K. The sublime and modern architecture: Unmasking (an aesthetic of) abstraction. New Lit. Hist. 1995, 26, 95-110. [CrossRef]

28. De Bruyn, F. Expressive Uncertainty: Edmund Burke's Theory of the Sublime and Eighteenth-Century Conceptions of Metaphor. In The Science of Sensibility: Reading Burke's Philosophical Enquiry; Springer: Dordrecht, Germany, 2012.

29. Cochrane, T. The emotional experience of the sublime. Can. J. Philos. 2012, 42, 125-148. [CrossRef]

30. White, L. Sublime Resources: A Brief History of The Notion of the Sublime. Luke White Home Page. Available online: http:/ / www.lukewhite.me.uk/sub_history.htm (accessed on 19 February 2021).

31. Korsmeyer, C. Fear and Disgust: The Sublime and the Sublate. Revue Int. Philos. 2008, 4, 367-379.

32. Williams, R.H. Notes on the Underground: An Essay of Technology, Society, and the Imagination; MIT Press: Cambridge, MA, USA, 2008.

33. Pallasmaa, J. The Social Commission and the Autonomous Architect. Harv. Archit. Rev. 1987, 6, 119.

34. Hepburn, R. 'Being' as a concept of aesthetics. Br. J. Aesthet. 1968, 8, 138-146. [CrossRef]

35. Godlovitch, S. Offending against nature. Environ. Values 1998, 7, 131-150. [CrossRef]

36. Hepburn, R. Landscape and the metaphysical imagination. In The Aesthetics of Natural Environments; Carlson, A., Berleant, A., Eds.; Broadview Press: Peterborough, ON, Canada, 2004; pp. 127-140.

37. De Bolla, P. Toward the Materiality of Aesthetic Experience. Diacritics 2002, 32, 19-37. [CrossRef]

38. Les Enfers_Par François de Nomé. Available online: https://commons.wikimedia.org/wiki/File:Les_enfers_-_par_Fran\%C3 \%A7ois_de_Nom\%C3\%A9_(dit_Mons\%C3\%B9_Desiderio).jpg (accessed on 21 March 2021).

39. Verne, J. Journey to the Center of the Earth; Penguin Books: London, UK, 1994.

40. Smith, M.; Davidson, J.; Cameron, L.; Bondi, L. Geography and Emotion-Emerging Constellations. In Emotion, Place and Culture; Smith, M., Davidson, J., Cameron, L., Bondi, L., Eds.; Ashgate Publishing: Farnham, UK, 2009.

41. Voyage au Centre de la Terre. Available online: https:/ / unframed.lacma.org/2013/12/12/right-place-right-action-right-timetadao-ando-and-walter-de-maria (accessed on 6 May 2021). 
42. Junghwa, L. Urban Subterranean Space: A link Between a Ground Level Public Space and Underground Infrastructure. Graduate Thesis, Rochester Institute of Technology, Rochester, NY, USA, 2018.

43. Princeton University Art Museum. Available online: https://artmuseum.princeton.edu/collections/objects/2969 (accessed on 28 March 2021).

44. Bate, W. From Classic to Romantic: Premises of Taste in Eighteenth-Century England; Harper Torchbooks: New York, NY, USA, 1961.

45. Funck, C.; Chang, N. Island in Transition: Tourists, Volunteers and Migrants Attracted by an Art-Based Revitalization Project in the Seto Inland Sea. Tour. Transit. 2018, 81. [CrossRef]

46. Soichiro, F.; Benesse, T.A. Showing the World a Way to Make Communities More Sustainable; Benesse Integrated Report; Benesse Holdings Inc.: Shinjuku, Japan, 2018; pp. 53-56.

47. Miwon, K. A Position of Elsewhere: Lessons From Naoshima; Naoshima, Nature.Art.Architecture; Hatje Cantz: Verlag, Germany, 2010.

48. Chung, H.; Lee, J. Community Cultural Resources as Sustainable Development Enablers: A Case Study on Bukjeong Village in Korea compared with Naoshima Island in Japan. Sustainability 2019, 11, 1401. [CrossRef]

49. Tadao, A. Chichu Art Museum; AXIS: Tokyo, Japan, 2004; pp. 77-79.

50. Benesse Art Site Naoshima. History of Benesse Art Site Naoshima. Available online: https://benesse-artsite.jp/en/art/chichu. html (accessed on 28 March 2021).

51. Corcoran, D. Right Place, Right Action, Right Time: Tadao Ando and Walter de Maria. Available online: www.unframed.lacma org/2013/12/12/right-place-right-action-right-time-tadao-ando-and-walter-de-maria (accessed on 21 March 2021).

52. Tadao, A. Naoshima; Exhibition Book; Le Bon Marche Rive Gauche: Paris, France, 2014.

53. Ando Tadao Architect-Ahngraphics. 2009. Available online: https://www.japan-experience.com/to-know/understandingjapan/the-architect-tadao-ando (accessed on 21 March 2021).

54. Tadao, A. Tadao, Ando-Process and Idea; TOTO: Tokyo, Japan, 2010. 